\title{
LOS LENGUAJES DE LA HISTORIA
}

Es sólito hablar de "el lenguaje de la matemática", "el lenguaje de la física", "el lenguaje de la biología", y hasta "el lenguaje de la ciencia", no en el sentido en que se habla de algunos de los muchos lenguajes llamados "naturales" o "corrientes" —el portugués o el checo, que son lenguajes, pero también, y más propiamente, lenguas-, sino en otro sentido: como un conjunto ordenable $y$, en última inståncia, formalizable, de expresiones -incluyendo algunas procedentes de uno o varios lenguajes naturales- que funciona de acuerdo con ciertos supuestos, métodos, reglas de inferencia, etc. No es que las expresiones 'lenguaje de la matemática', 'lenguaje de la biología' y, no digamos, 'lenguaje de la ciencia' no planteen problemas. Doy por sentado, sin embargo, que no son intratables, e inclusive que algunos han sido despachados con gran diligencia. En todo caso, los matemáticos, los físicos y los biólogos no suelen arremeter contra sus colegas con el cuento de que son unos impostores. Los intuicionistas y los formalistas pueden andar a la greña: cada uno de estos grupos reprocha a sus contrincantes no practicar el género de matemáticas apropiado. Los mecanicistas y los organicistas pueden disputar acerca de cuál es el tipo de biología que conviene fomentar. Pero a ninguno se le ocurre - salvo en efímeros instantes de malhumoracusar a sus colegas de no ser, en rigor, colegas, es decir, de no cumplir con su deber. Los propios filósofos, que son particularmente exigentes cuando se trata de los demás, no pretenden que los hombres de ciencia no hagan ciencia; a lo sumo, se complacen en poner de relieve que no se dan cuenta, o no se preocupan, de los supuestos sobre los cuales montan sus respectivas ciencias, o que no son lo bastante afinados y precisos en el manejo de los conceptos.

No ocurre lo mismo en materia de historiografía. No sólo los filósofos, sino a menudo los propios historiadores, claman que Fulano de Tal, que puede hasta figurar en los registros académicos como un historiador eminente, no hace, propiamente hablando, historia, sino a lo sumo seudo-historia. $Y$, en verdad, cabe preguntarse qué quiere decir hacer historia, cuando por 'historia' —o, mejor dicho, por 'historiografía'- se entienden cosas muy diversas. Recorramos (con la imaginación) las salas, corredores, sótanos, áticos y recovecos de una inmensa y abrumadora biblioteca que contenga todos los libros, folletos, artículos, ensayos, repertorios, etc., que se hayan escrito hasta el momento (cualquier momento) y que sean clasificables, de acuerdo con los cánones habituales, bajo acápites como "Escritos históricos", "Trabajos de. historia", "Historiografía", etc. Aun si por 'historia' se entiende solamente 'historia humana' y no cualquier otra especie de "historia" - por ejemplo, 
la titulada durante mucho tiempo "historia natural"- - , no se tarda en quedar sobrecogido por la multitud y variedad de tales producciones.

La cosa no es para menos. La supuesta biblioteca alberga toda suerte de engendros: crónicas; biografías; autobiografías; descripciones de acontecimientos por testigos (o supuestos tales); listas de descubrimientos arqueológicos; repertorios de inscripciones y de documentos; historias de naciones o de Estados; historias de tal o cual período de una nación o de un Estado; historias de épocas; historia diplomática; de partidos políticos, instituciones de toda clase, iglesias, sectas, clases sociales, guerras, revoluciones, tratados de paz, semanas más o menos trágicas; historias universales; prehistorias; historias de ciudades, regiones, condados, comarcas y villorios. Alberga también historias de determinadas actividades humanas: historias de la industria y del comercio, de la agricultura, del arte, de la religión, de la filosofía, de la ciencia, de la técnica y, claro está, de innumerables divisiones y subdivisiones de cualesquiera actividades y disciplinas: historias de la lógica, de la metafísica, de la música, de la química, de la genética, de la gramática. Historias, además, de actividades y disciplinas en tales o cuales comunidades o épocas: historias de la ética medieval, de la música escandinava o de la pintura renacentista. La lista va en camino de ser interminable: caben historias de las supersticiones, de la lucha contra las supersticiones, de las enfermedades, del arte cisoria, de la poesía infantil, del género chico, de los gustos culinarios, etc. Los propios escritos históricos pueden convertirse en materia histórica: hay historias de métodos históricos, de la historiografía, de las vicisitudes de la conciencia histórica y, naturalmente, historias de tales historias, junto con bibliografías de todas ellas, y bibliografías de bibliografías, e historias de tales bibliografías, e inclusive posiblemente alguna historia relatando el asombro, la perplejidad, el mareo experimentados por ciertas personas que visiten imaginariamente bibliotecas imaginarias que contengan tantas y tantas historias y, en momento oportuno, la historia de tales historias.

Las dudas parecen legítimas: ¿es todo eso realmente historiografía? ¿En qué consiste escribir historia? Historiadores y, ni que decir tiene, filósofos interesados en la historia, no pueden evitar almacenar sospechas y recelos; hay que poner en claro de una vez para siempre lo que es, propiamente hablando, historiografía a diferencia de lo que no.lo es, aunque -y éste es el problema - parezca serlo. De ahi cierto número de propuestas acerca de lo que es una historiografía digna de este nombre. De estas propuestas entresacamos, a modo de ejemplo, las siguientes:

1) Los historiadores tienen que "atenerse a los hechos" y no preocuparse en lo más mínimo acerca de lo que "significan". Los hechos son hechos, y ahí se termina la historia. La auténtica historiografía consiste, según la célebre frase de Ranke, en "contar lo que realmente ha sucedido". 
2) No hay, en verdad, "puros hechos históricos", porque todo hecho histórico está ligado a uno o varios significados. Como no se puede contar o narrar todo, hay que seleccionar lo que se cuenta o narra. Pero esto es ya una interpretación de los supuestos "puros hechos". Por si ello fuera poco, no se puede decir sin más ni más que los hechos son históricos. Los hechos llegan más bien a ser históricos, como lo prueba el que ciertos hechos que en el momento $X$ parecían no tener $-\mathrm{y}$ por ventura no tenían - ningún sentido o significado históricos, en el momento $X+1$ ó $X+2$ manifestaron ser históricos.

3) Los historiadores deben ocuparse de acontecimientos o sucesos y no preocuparse por los propósitos, las ideas o los sentimientos de los seres humanos al respecto. Al fin y a la postre, sentimientos, ideas $\mathrm{y}$, sobre todo, propósitos pueden contraponerse, y a menudo se contraponen, a los sucesos o acontecimientos.

4) Los historiadores deben prestar atención prominente a lo que Collingwood llamó "pensamientos" de los seres humanos. Los titulados "hechos históricos" son de carácter "interno". El que Julio César cruzara el Rubicón no es, por sí mismo, un hecho histórico; lo es, en cambio, el "pensamiento" -si se quiere, la "intención"- de Julio César al cruzar el Rubicón.

5) Los historiadores deben tratar el material histórico científicamente, y hacerlo, además, de un modo igual o, cuando menos, similar al del hombre de ciencia, físico, químico, biólogo. Lo que importa en historia es el modo o modos como los ejemplos particulares resultan abarcados por leyes - "cubiertos" por leyes. Ello no quiere decir necesariamente que la historia posea leyes propias; quiere sólo decir que los historiadores deben echar mano de leyes con el fin de presentar los hechos.

6) Puesto que los hechos o acontecimientos históricos son únicos, absolutamente singulares e irrepetibles, los historiadores deben renunciar a la ilusión de someterlos a leyes. La tarea del historiador es puramente descriptiva; no es legítimo confundir la historiografia con ninguna ciencia, y específicamente con ninguna ciencia natural.

Todas estas propuestas, con las pertinentes recriminaciones, presuponen cierta noción de lo que es un hecho o acontecimiento histórico, pero como esta presuposición está ligada a su vez al problema de qué tipo, o tipos, de lenguaje cabe usar en historiografía, cabe tratar nuestro asunto adoptando un punto de vista "lingüístico". A ello vamos de inmediato.

Característico de cualesquiera de las propuestas reseñadas es que hay un, y solamente un, lenguaje propiamente historiográfico. Según algunos, es el lenguaje de la "crónica": la historiografía es fundamentalmente una colección de documentos más o menos razonablemente ordenados y sin ningún orden sobreimpuesto a ellos, esto es, sin ninguna interpretación, o inclusive selec- 
ción. Según otros, es el lenguaje de la "verdadera historia" o "historia significativa", la cual puede servirse de la crónica, pero es todo lo contrario de una "mera crónica". Algunos claman que el lenguaje historiográfico es el de los "hechos abarcados por leyes", o el de la explicación histórica -en un sentido rigurosamente científico de 'explicación'. Varios indican que el lenguaje del historiador tiene que ser puramente descriptivo; otros, que ha de ser fundamentalmente explicativo; otros, que no puede ser sino interpretativo. $\mathrm{Y}$ así sucesivamente.

Frente a todas y a cada una de las propuestas en cuestión, sentaré la siguiente declaración de principios: la historiografía no está uncida a ningún "lenguaje" determinado. No está tampoco subordinadà a ningún sentido específico y univoco de la expresión 'hecho histórico'. Los historiadores examinan diferentes tipos de hechos, y lo hacen en diversos lenguajes. Con ello admito que toda expresión usada (con la debida buena fe) por un historiador competente es un ejemplo adecuado de lenguaje historiográfico. En vez de recomendar al historiador lo que tiene que hacer con el fin de llevar cumplidamente a cabo su tarea, reconozco de buen grado que, salvo en excepcionales circunstancias, los historiadores saben lo que se traen entre manos. Por tanto, hay que empezar por examinar lo que los historiadores hacen, y el lenguaje, o lenguajes, que usan.

Ahora bien, creo que echan mano de tres distintos tipos de lenguaje. No los usan sucesivamente, sino más bien entretejidos en una intrincada trama. La historiografía es, desde este punto de vista, una compleja mezcla de tipos de enunciados. Estos se encuentran en cualquiera de las formas de historiografía antes mencionadas, pero se manifiestan más nítidamente en las historias de una determinada comunidad humana. En virtud de ello, entresacaré de esta forma de historia los ejemplos de los tres tipos de lenguaje.

Llamaré a éstos simplemente, Lenguajes I, II y III, y comenzaré en cada caso con algunos ejemplos.

Del lenguaje I cabe dar los ejemplos siguientes:

El telegrama que Bismarck envió, o hizo enviar, desde Ems, se comunicó al público el 12 de junio de 1870 .

Felipe II fue Rey de España,

Constantinopla fue tomada por los turcos en 1453.

Se observará que todos estos enunciados hablan de alguna entidad particular o de algún acontecimiento particular, o ambos a un tiempo. No pueden, pues, equipararse a otros enunciados como:

El atún es negro azulado por encima y gris plateado por debajo,

El frambueso tiene hojas verdes por encima y blancas por el envés,

El clarín es un instrumento de viento de sonidos agudos, los cuales hablan de clases de entidades particulares, o describen estas entida- 
des por medio de nombres de clases. No pueden tampoco equipararse a enunciados como:

La distancia entre la Tierra y la Luna en el instante $t$ es de $34^{8} .75^{6}$ kilómetros,

pues aunque aquí se habla de un acontecimiento particular - sobre todo si se supone que hay un, y sólo un instante, en el que la distancia entre la Tierra y la Luna es de $34^{8.756}$ kilómetros-, tal acontecimiento desempeña una función distinta de los descritos en enunciados historiográficos del Lenguaje I: la de ser una condición inicial dentro de un sistema. Los enunciados del Lenguaje I no describen condiciones iniciales ni son tampoco derivables de éstas más leyes generales. Ello ocurriría únicamente si hubiese leyes específicamente históricas que permitieran predicciones, siquiera de carácter probabilitario o estadístico, cosa que está muy lejos de ser obvia. Cabría más bien equiparar los enunciados del Lenguaje I a otros como:

Antonio del Valle empezó a jugar al ajedrez a los cinco años,

La casa propiedad de Edmundo Reno fue derribada para construir un teatro,

pero entonces habría que averiguar no sólo si se trata de enunciados lógicamente equiparables a los del Lenguaje I, sino también, y sobre todo, si son históricos. El que lo sean o no depende de ciertos criterios en los que no podemos detenernos aquí; baste consignar que ninguno de tales criterios es jamás completamente suficiente en virtud de la permanente posibilidad de que un hecho "llegue a ser" histórico.

Más importante que dichas analogías o diferencias con respecto a otros tipos de enunciados, es que los del Lenguaje I, cuando son, o llegan a ser reconocidos, como históricos, pueden verificarse mediante el examen de documentos -en un sentido muy amplio de 'documentos', que incluye testigos. Semejante verificación no es necesariamente fácil o simple; puede, y suele, comportar un conocimiento muy amplio y detallado de muchas cosas. Pero una vez en posesión de este conocimiento, puede procederse a esta verificación en última instancia "directa": el telegrama de Bismarck se hizo público en tal o cual fecha si, efectivamente, se hizo público en tal o cual fecha.

Los enunciados del Lenguaje I se refieren a acontecimientos que son presentados, o presentables, como tales acontecimientos. En una acepción muy amplia, podemos calificar a estos enunciados de "descriptivos". Formular el enunciado puede, y suele, requerir un previo conocimiento histórico nada desdeñable. Para empezar, el acontecimiento del cual habla el enunciado es histórico sólo porque se halla insertado dentro de algún complejo de acontecimientos a su vez juzgado histórico. Esto es, por supuesto, un círculo vicioso, porque el complejo de referencia es histórico sólo en tanto que se halla compuesto de acontecimientos históricos, pero no veo modo de salir de este círculo. En todo caso, es dentro de él que nuestros enunciados se refieren a 
acontecimientos "directamente" verificables: Bismarck hizo lo que consta que hizo; Felipe II fue Rey de España; y Constantinopla fue tomada por los turcos el mismo año en que cayó.

Es tentador llamar a los enunciados del Lenguaje I "atómicos", pero si así se procede hay que precisar lo que con ello se entiende: se entiende sólo que, dentro de un determinado complejo histórico, no son susceptibles de ulterior análisis y descomposición. No son "atómicos" en ningún otro sentido. En efecto, el hecho de que Constantinopla fue tomada por los turcos en 1453 implica muchas "cosas" - muchos turcos, muchos bizantinos, muchas armas, muros, etc., etc. Es razonable pensar que la "atomicidad" de un acontecimiento histórico no es nunca definitiva, por cuanto depende del uso que se hace del enunciado correspondiente; un enunciado atómico dentro de un contexto puede, en efecto, no serlo dentro de otro.

Del lenguaje II cabe dar los siguientes ejemplos:

La política seguida por Bismarck fue la causa principal de la guerra franco-prusiana de 1870 ,

Felipe II defendió la fe católica contra Inglaterra,

La caída de Constantinopla marcó el fin del Imperio bizantino.

A diferencia de lo que sucede con los enunciados del Lenguaje I, no hay documentos por medio de los cuales puedan verificarse los enunciados citados del Lenguaje II. Sin embargo, pueden verificarse en uno o varios sentidos estableciendo, por ejemplo, ciertas relaciones causales, o describiendo propósitos o consecuencias de propósitos, o examinando lo que quedaba de un imperio, o escrutando los actos y las decisiones políticas de un poder nuevo. Si se sigue hablando de verificación, no cabe admitir, pues, una verificación "simple", o verificación de "uno a uno", sino una de índole muy compleja, o verificación múltiple. En suma, con el fin de determinar la validez, o falta de validez, de las aserciones correspondientes tenemos que traer a colación intenciones políticas, leyes demográficas, luchas ideológicas, relaciones económicas, etc., etc.

No todos los enunciados del Lenguaje II son de indole explicativa. Pero muchos lo son. Puede afirmarse, por tanto, que son enunciados "generalmente explicativos", mas sin pretender con ello agotar su naturaleza. En rigor, es muy difícil, por no decir imposible, dar con un adjetivo que califique todos los enunciados de tal lenguaje.

Los enunciados aquí dilucidados no son mero resultado de yuxtaponer enunciados del Lenguaje I. Lo serian si la historia fuese simplemente una serie de hechos o acontecimientos, y si la historiografía consistiera en disponerlos en ristre. Por otro lado, no puede afirmarse que los enunciados del Lenguaje II sean resultado de una previa interpretación que afecta al complejo histórico dentro del cual se inserte. Es cierto que tales enunciados exhiben con frecuencia un status incierto y algo desdibujado; prueba de ello 
es que pueden formularse de modos distintos (en vez de "La política seguida por Bismarck fue la causa principal de la guerra franco-prusiana de $1870^{\circ}$ podemos decir, por ejemplo, "La política seguida por Bismarck alteró la balanza de poder europea que prevaleció hasta 1870"). Pero el que posean un status incierto no quiere decir que puedan reducirse a otros tipos de enunciados. Es plausible afirmar que estos enunciados son, en gran medida, de carácter causal o "intencional", es decir, que enuncian causas o intenciones (o ambas), pero no está excluido que puedan desempeñar otras funciones.

No siendo los enunciados del Lenguaje II resultado de una yuxtaposición de enunciados del Lenguaje I, no pueden ser considerados tampoco como sumarios de éstos. Así, describir los actos y las decisiones de Felipe II, las turbias intrigas en torno a Antonio Pérez, la construcción de la Armada, la derrota de la Armada, etc., no sería todavía una garantía suficiente para afirmar que Felipe II defendió la fe católica contra Inglaterra.

Del Lenguaje III cabe dar los siguientes ejemplos:

La guerra franco-prusiana reveló la unidad de Europa mediante la existencia de un conjunto de tensiones económicas e ideológicas,

Con Felipe II comenzó la decadencia de España y comenzó la expansión imperial de Inglaterra,

Con la calda de Constantinopla desapareció el último bastión de la cultura antigua.

Se han introducido aquí ciertos términos - 'decadencia', 'expansión', 'cultura' (o 'civilización'), 'unidad', 'tensión'- y se han implicado algunos otros - 'progreso', 'auge', etc. Puede argüirse que ello ha sido una metedura de pata, y que los historiadores deberían abstenerse cuidadosamente de echar mano de términos semejantes. El problema es cómo es posible escribir la historia de una nación, de una comunidad humana, de una civilización, etc., sin el uso (siquiera parsimonioso) de estos u otros términos análogos.

Estimo que no hay peligro en recurrir a ellos si se tiene en cuenta el papel que desempeñan en historiografía. No son, a mi entender, puros sfmiles o metáforas. Pero no son tampoco descripciones, o inclusive explicaciones, "literales". En efecto, ningún "documento" de ninguna clase puede verificar enunciados del Lenguaje III. No hay documentos históricos que verifiquen que ha habido unidad, expansión, progreso, decadencia, etc.; hay, a lo sumo, documentos históricos en los que ciertas personas afirman que ha habido o no unidad, expansión, etc., etc. La verificación no puede efectuarse tampoco por medio de explicaciones causales o intencionales del tipo de las exhibidas en los enunciados del Lenguaje II. Por tanto, no hay empacho en concluir que los enunciados del Lenguaje III son "inverificables".

Ello no equivale a decir, empero, que sean gratuitos. Estos enunciados funcionan, en efecto, con respecto a la historia, de modo similar a como ciertos enunciados relativos a una vida humana funcionan con respecto a ésta. 
Cuando se habla de una persona es posible, y hasta deseable, introducir términos como 'vocación', 'vitalidad', 'abulia', 'conflicto', etc. - los cuales pueden traducirse, desde luego, a vocablos psicológicos, pero mantenerse asimismo como términos biográficos. Por medio de éstos hacemos alusión a lo que hay en la vida humana de dramático, en un sentido de 'dramático' que no tiene necesariamente nada de patético. Todo ello presupone que damos, o intentamos dar, una interpretación de la vida humana. Análogamente con la historia, y especialmente con la de una comunidad que sea plenamente "historiable". Sin duda que semejantes interpretaciones deben introducirse parsimoniosamente y que tienen que confrontarse siempre con los hechos, los acontecimientos, las secuencias causales y las explicaciones a que antes nos hemos referido. Si se quiere, los enunciados del Lenguaje III deben confrontarse siempre con los de los Lenguajes I y II. Esto no quiere decir que éstos sean capaces de verificar estrictamente aquéllos, pero cuando menos no deben invalidarlos. La relación entre los enunciados del Lenguaje III y los de los Lenguajes I y II es, por ello, sumamente delicada. Puesto que estos últimos no deben invalidar aquéllos, cabe decir que en cierto modo los verifican. Pero lo único que verifican en su posibilidad, no su verdad. De los enunciados de los Lenguajes I y II no se pasa a los del Lenguaje III, ni inductiva ni deductivamente. Los enunciados del Lenguaje III son posibles, pues, sólo dentro del marco trazado por los enunciados de los Lenguajes I y II. Este marco es, sin embargo, muy amplio. Por eso las interpretaciones históricas - que constituyen el grueso de los enunciados del Lenguaje IIIson varias, pero no infinitas, $\mathrm{y}$ tampoco indeterminadas.

Algunos pensadores proclaman que no es negocio de la filosofía cambiar nada, y que la filosofía tiene que dejar las cosas tal como están. No comparto esta opinión en todos los casos, pero en el que nos ocupa estoy enteramente en favor de la no intervención. Lo único que puede, y debe, hacer el filósofo con respecto a la historiografía es analizar lo que practican los historiadores dignos de este nombre. Además del problema de los tipos de enunciados por ellos usados, hay muchos otros que una filosofía analítica de la historia puede dilucidar. Pero debe hacerlo sin pretender que los historiadores alteren sus métodos y hábitos - lo único que se puede pretender que los historiadores cambien son sus opiniones sobre lo que es la historia. No hay razón para que los filósofos traten a los historiadores de modo distinto a como tratan a los físicos. Aun dejando, en historiografía, las cosas como están -y, por descontado, como irán estando-, queda todavía mucho que decir sobre ellas.

JOSÉ FERRATER MORA 